
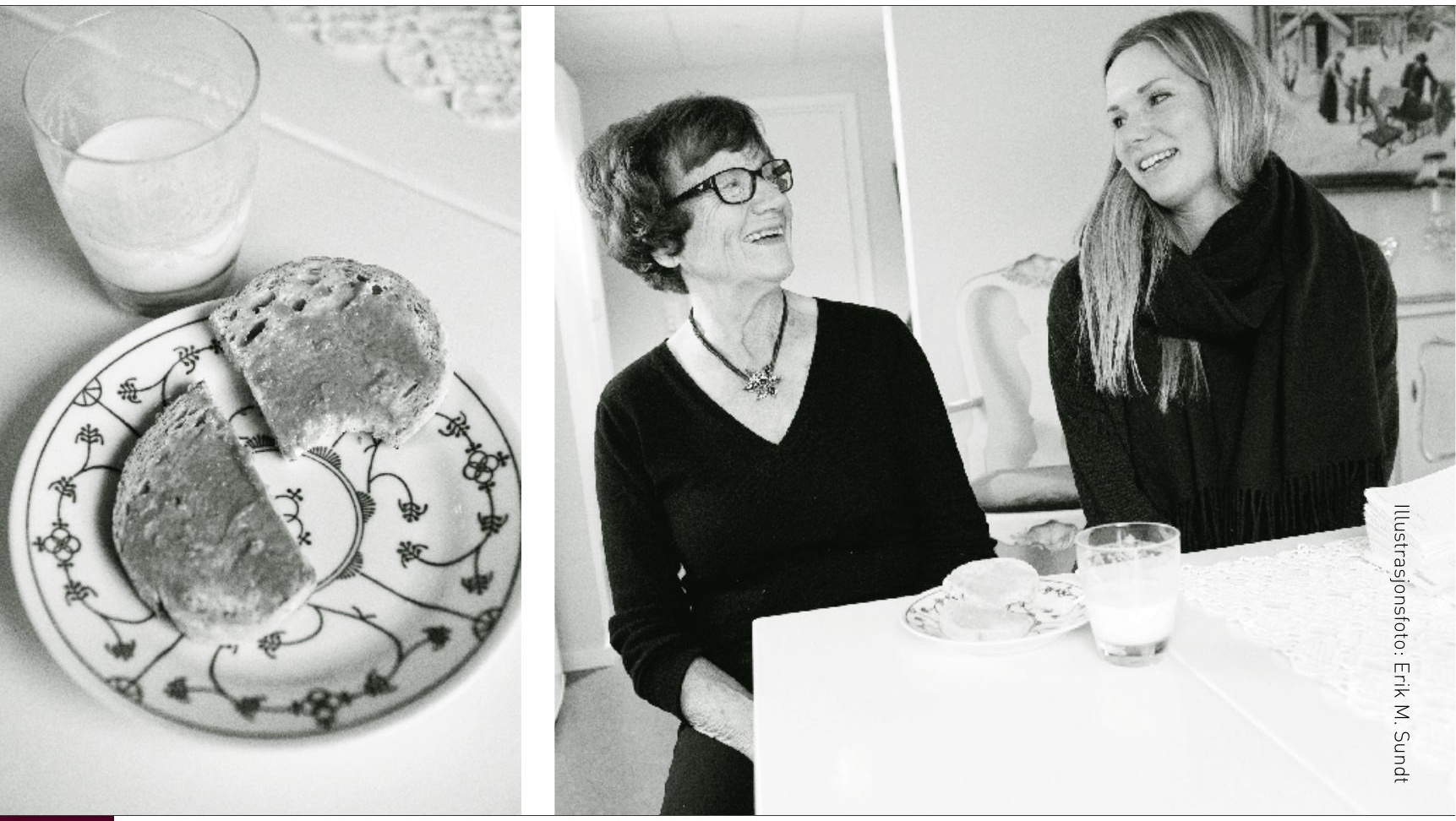

Bakgrunn: Eldre personer med hukommelsestap er svært utsatt for underernæring. Tidligere studier har i hovedsak fokusert på pasienter som bor på institusjon.

Hensikt: Hensikten med denne studien er å kartlegge og belyse ernæringsstatusen til eldre hjemmeboende pasienter med demens og kognitiv svikt som făr bistand av hjemmetjenesten i fire bydeler i Oslo.

Metode: Det ble gjennomført en tverrsnittsstudie i fire utvalgte bydeler i Oslo, (N=282). Instrumentet Mini Nutritional Assessment (MNA) ble benyttet til innsamling av data. Logistisk regresjonsanalyse ble anvendt for å analysere dataene, og resultatene presenteres i oddsratioer.

Resultater: Studien viser at underernæring er svært utbredt blant hjemmeboende pasienter med kognitiv svikt og demenssykdom. Omkring halvparten av pasientene var underernært eller sto i fare for underernæring. Det å være kvinne og ha problemer med matinntak viser seg å være viktige risikofaktorer for underernæring.

Konklusjon: Resultatene i studien viser at det er avgjørende at helsepersonell og pårørende er kjent med risikofaktorene for underernæring. Nødvendige tiltak må iverksettes på et tidlig stadium for å forhindre alvorlig underernæring og sykdom som følge av dette.
Malnutrition in elderly people living at home with cognitive impairment and dementia

Background: Elderly people with memory loss are particularly vulnerable to malnutrition. Previous studies have mainly focused on elderly living in an institution.

Objective: The purpose of this study is to identify the nutritional status of elderly with dementia who live at home.

Method: The survey design was conducted in four selected districts in Oslo ( $N=282)$. Mini Nutritional Assessment Instrument (MNA) was used for data collection. Logistic regression analysis was used to analyze the data and the results were presented in odds ratios.

Results: Our results show that malnutrition is highly prevalent among home-living patients with cognitive impairment and dementia. About one-half of the patients were malnourished or were at risk of malnutrition. Being a woman and having problems with food intake appears to be important risk factors for malnutrition.

Conclusion: One interpretation of these results is that it is essential that health professionals and the patients' relatives are aware of these risk factors, and that necessary measures are implemented at an early stage, in order to prevent severe malnutrition and subsequent disease.

Keywords: Elderly, dementia, nutrition, home nursing. 


\section{Underernzering hos eldre hjemmeboende personer med demens}

Forfattere: May-Karin Rognstad, Idunn Brekke, Eva Holm, Cecilie Linberg og Nina Lühr

\section{NøKKELORD}

- Eldre

- Demens

- Ernæring

- Hjemmesykepleie

\section{INTRODUKSJON}

Eldre personer med betydelig hukommelsessvikt er spesielt utsatt for vekttap og problemer relatert til måltider. Dårlig kosthold og dehydrering kan gi redusert hukommelse (1). Det er særlig syke og hjemmeboende pasientene med demenssykdom som er i risikogruppen for å utvikle underernæring (1-2). I denne artikkelen vil vi fokusere på ernæringsstatusen hos eldre hjemmeboende pasienter med demenssykdom og pasienter med kognitiv svikt knyttet til hukommelsestap som trenger tilrettelegging av hjemmetjenesten. Demens er en fellesbetegnelse for flere hjernesykdommer som fører til kognitiv svikt relatert til hukommelsestap. Sykdomsforløpet kan variere. Verktøyet som brukes for å utrede demens er todelt. Først kartlegges pasientenes situasjon og den mentale funksjonen testes ved faktaspørsmål og Mini mental statustest (MMS) (3). Deretter bruker man informasjonen dette gir til å stille diagnose. Dette er en tidkrevende prosess. I studiens utvalg har vi både pasienter med diagnosen demenssykdom og pasienter uten diagnose, men med kognitiv svikt, som har behov for variert grad av bistand fra hjemmetjenesten.

Norske studier $(2,4-6)$ viser at forstyrret appetitt og spiseatferd er et betydelig problem hos eldre hjemmeboende med demens. Studiene viser at det er viktig å kartlegge mat- og drikkeinntak ved å lage en oversikt over mengde og typer væske som inntas. Redusert appetitt kan være det første subjektive og kliniske tegnet på vekttap og fare for underernæring (5). Man understreker spisesituasjonens betydning og at tilrettelegging, måltidsmiljø og sosial interaksjon kan være tilstrekkelig for mange med demenssykdom for å oppnå økt energiinntak, trivsel og fysisk funksjon $(2,5)$.

Lov om kommunale helse- og omsorgstjenester (7) har som formål blant annet «å sikre at tjenestetilbudet blir tilrettelagt med respekt for den enkeltes integritet og verdighet». Tilbudet skal tilpasses den enkeltes behov. Loven beskriver et minstemål for hva kommunen skal levere av tjenester til pasientene, det vil si den hjelp og omsorg pasientene har krav på fra kommunene eller bydelene. Helsedirektoratet slår fast at helseforetakene og kommunene skal sikre at ernæring blir en integrert del av behandlingstilbudet i helse- og omsorgstjenesten. Blant hjemmeboende syke

\section{Hva tilfører artikkelen?}

Undersøkelsen viser at mange hjemmeboende eldre står i fare for å bli underernært og at kvinner er særlig utsatt.

\section{Mer om forfatterne:}

May-Karin Rognstad er førsteamanuensis, Dr.philos. ved Høgskolen i Oslo og Akershus. Idunn Brekke er førsteamanuensis, PhD. Sosiologi ved Høgskolen i Oslo og Akershus. Eva Holm er fagutviklingssykepleier i geriatri ved GERIA, Oslo kommunes ressurssenter for demens og alderspsykiatri. Cecilie Linberg er spesialsykepleier i geriatri, Cathinka Guldbergsenteret Lovisenberg. Nina Lühr er ergoterapeut, fag-, kvalitet og utviklingsleder, Bydel Sagene, hjemmetjenesten. Kontaktperson: maykarin.rognstadahioa.no 
eldre anslår man at forekomsten av underernæring ligger på rundt 10 prosent (8).

Flere studier på demens fokuserer på ernæring og kliniske tegn på vekttap og fare for underernæring hos eldre pasienter i sykehjem (9-14). tigste faktorene som påvirker eldres helse (12). De nevnte studiene viser at eldre ofte har dårlig ernæringsstatus før sykdom oppstår. Videre viser en oppfølgingsstudie at kvinner ser ut til å være mer utsatt for underernæring enn menn (15). Bioletta og kolleger (16) viser til omsorgsgiveres utfordrende rolle når det gjelder å tilføre tilstrekkelig ernæring for å unngå vekttap hos eldre pasienter med Alzheimers sykdom. Studier framhever at faktorer dårlig tannstatus og situasjonen rundt måltidet, for eksempel det å spise alene, øker sannsynligheten for lavt matinntak og utilsiktet vekttap (17-19). Personer som bor alene kan ofte være Underernæring er en av de viksom dårlig appetitt, glemsel,

spise eller å ta medikamenter, noe som kan påvirke den sosiale interaksjon med personalet som assisterer dem under måltidet.

Aselage (22) framhever at endring i atferd relatert til vansker med å spise mat, motsette seg assistanse og annen uønsket atferd under måltid, krever at man identifiserer og vurderer pasienten med tanke på underernæring. Studier viser at problemer kan oppstå mellom personer med demenssykdom og omsorgsperson som bistår under måltidet $(23,24)$. Kommunikasjon mellom omsorgsperson og den hjelpetrengende er viktig for å gjøre måltidet til en positiv opplevelse. En studie av sykepleiere og andre omsorgsgivere i sykehjem beskriver omfattende utfordringer. Dette gjelder særlig å kommunisere med og tilføre tilstrekkelig ernæring til pasienter med demenssykdom eller kognitiv svikt for at de skal unngå vekttap (25).

Mange studier beskriver vekttap og underernæring hos

\section{En viktig kilde til glede hos eldre er mat.}

utsatt for de nevnte faktorer.

En viktig kilde til glede hos eldre er mat, og derfor er det en oppgave for helsearbeidere å stimulere denne gleden hos pasientene sine så lenge som mulig (20). Watson (21) identifiserte problemer knyttet til ernæring ved å definere begrep som «feeding» (mate) og «eating» (spise) i litteraturen som omhandler spiseatferd og måltidsatferd. En oversiktsartikkel (22) anvender de nevnte domenene. Faktorer som tannhelse og svelgeproblemer kan føre til uønsket atferd hos personer ved at de nekter å eldre personer på sykehjem med kognitiv svikt. Flere faktorer framheves som årsak til underernæring, som atferdsproblematikk knyttet til spising, mating eller selve måltidet. Få studier er gjennomført der man har sett på ernæringsstatusen hos eldre, hjemmeboende personer med demenssykdom eller kognitiv svikt.

I denne studien vil vi studere ernæringsstatus hos eldre personer med demenssykdom eller kognitiv svikt som får bistand av hjemmetjenesten. Hensikten med studien er å kartlegge og belyse ernæringsstatusen til eldre hjemmeboende pasienter med demens og kognitiv svikt som får bistand av hjemmetjenesten i fire bydeler i Oslo.

Følgende to forskningsspørsmål stilles i denne studien:

- I hvilken grad forekommer underernæring blant eldre hjemmeboende pasienter med demenssykdom eller kognitiv svikt?

- Hvilke risikofaktorer for underernæring peker seg ut som særlig sentrale hos denne utsatte pasientgruppen?

\section{METODE \\ Design}

For å besvare forskningsspørsmålene benyttet vi en tverrsnittsstudie med kartlegging ved hjelp av spørreskjema. Studien ble gjennomført i 2012.

\section{Utvalg}

Inklusjonskriterier er eldre, hjemmeboende pasienter med demenssykdom eller kognitiv svikt, 67 år og eldre som skåret 3-5 på IPLOS- (individbasert pleie og omsorgsstatistikk) skalaen med variabelen «hukommelse», og som mottar kommunale helsetjenester i hjemmet. Antallet pasienter med demensdiagnose er ikke registrert, men felles for pasientene i utvalget er deres hukommelsessvikt, som i ulik grad gjør dem avhengige av bistand fra hjemmetjenesten. IPLOS-skalaen er en del av dokumentasjonssystemet GERICA. IPLOS-skalaen med variabelen «hukommelse» henviser til pasientens behov for bistand til å huske inntrufne hendelser, finne fram, være orientert for tid og sted. 1-2=lite eller ingen bistand, $3=$ middels behov for bistand, $4=$ stort behov for bistand og $5=$ full bistand. Totalt $\mathrm{i}$ de fire 
bydelene var det 445 pasienter som skåret 3-5 på IPLOSskalaen. Eksklusjonskriterier: pasienter som skårer 1-2 på IPLOS-skalaen. Totalt i de fire bydelene var det registrert langt flere kvinner enn menn, 138 menn og 307 kvinner, i alt 445 pasienter. I vår studie deltok 282 (80 menn og 202 kvinner) av de 445 pasientene. Årsaken til at ikke alle 445 pasienter ble tatt med, var at noen var syke og andre ikke ville delta. Pasienter som var syke skilte seg ikke ut fra gruppen som ble inkludert i studien, heller ikke aldersmessig. Det er velkjent at pasienter med kognitiv svikt eller demenssykdom kan ha en betydelig varierende dagsform. Den totale svarprosenten i de fire bydelene var 63,4.

\section{Datainnsamling}

For å vurdere ernæringsstatusen til pasienter med demenssykdom eller kognitiv svikt, har vi benyttet instrumentet Mini Nutritial Assessment (MNA). Flere studier viser at MNA er et nyttig instrument for å identifisere underernæring hos eldre hjemmeboende personer $(12,20,26)$. MNA er etablert som et av de mest valide og oftest anvendte instrumentene ved screening av eldre personers ernæringssituasjon. MNA er derfor en anbefalt del av en omfattende geriatrisk vurdering og spesifikt utviklet for å vurdere eldre personer $(8,18,24)$. I denne artikkelen benytter vi det nevnte MNA-skjemaet til innsamling av data og for å måle underernæring og fare for underernæring.

MNA-skjemaet består av to deler: Screening del I som består av seks spørsmål og screening del II som består av tolv spørsmål knyttet til underernæring.
MNA del I, består av seks spørsmål om:

- Matinntaket har gått ned i løpet av de tre siste månedene på grunn av nedsatt appetitt, fordøyelsesproblemer, vanskeligheter med å tygge eller svelge

- Vekttap i løpet av de tre siste månedene

- Mobilitet

- Opplevd psykologisk stress eller akutt sykdom i løpet av de tre siste månedene

- Nevropsykologiske lidelser

- Kroppsmasseindeks (KMI)

MNA del II inneholder spørsmål om:

- Bolig

- Medikamentforbruk

- Sår

- Antall måltider per dag

- Proteininntak

- Inntak av frukt og grønt

- Væskeinntak

- Spisemåte

- Syn på egen ernæringsstatus,

- Syn på egen helse

- Overarmens omkrets

- Leggens omkrets

En viktig årsak til at vi har valgt å benytte instrumentet MNA er fordi det er enkelt i bruk, uten bruk av invasive metoder og at det er et godt validert screening-instrument (27). MNA er også brukt i norske studier $(28,29)$. En annen årsak til at vi har valgt å benytte MNA er at Oslo kommune allerede har valgt MNA-instrumentet til kartlegging av ernæringsstatus hos sine pasienter. Det ble besluttet i prosjektgruppen å utforme et tilleggsskjema for innsamling av flere tilleggsdata og bakgrunnsdata med følgende variabler: daglige aktiviteter, boform, boligtype, innkjøp av mat, inntak av mat, bistand, IPLOS-registrering. Prosjektgruppen besto av fire koordinatorer fra hver bydel og leder for prosjektet fra Høgskolen i Oslo og Akershus.

Før start av datainnsamling, gikk hver av de fire koordinatorene gjennom MNA-skjemaet, og vurderte hvordan det skulle fylles ut. Deretter ble det holdt forelesning om kosthold og ernæring for alle sykepleierne og hjelpepleierne som hadde ansvar for å samle data hos sine «faste» pasienter i de fire bydelene. De fire koordinatorene fungerte også som motivatorer for personalet som deltok i datainnsamling og samlet inn utfylte skjemaer som ble videreført til leder for prosjektet. MNA-skjemaet ble utfylt hjemme hos pasientene. Pleierne leste opp spørsmål fra skjemaet som pasientene besvarte. For pasienter som skåret 5 på IPLOS-skalaen var det pleieren som vurderte pasienten.

\section{Analyse}

I denne studien benyttes logistisk regresjonsanalyse. Den avhengige variabelen $i$ analysene er ernæringsstatus. Det skilles mellom to utfall: $1=$ underernært eller i fare for underernæring og $0=$ normal/ikke $\mathrm{i}$ faresonen. En person er definert som normal/ikke i faresonen for underernæring hvis han/hun skåret 12 poeng eller mer i del I av MNA-screeningen. De som skåret 23,5 poeng eller mindre på MNA-screening del II regnes som underernærte eller i fare for å bli underernærte.

Vi benytter en rekke uavhengige variabler $\mathrm{i}$ analysen. De inkluderte variablene er valgt ut fordi tidligere studier har vist at de har betydning for ernæringsstatus. Kjønn er kodet 0 for kvinner og 1 for menn. Variabelen IPLOS-registrering skiller mellom $0=$ middels behov for bistand og 1=stort behov eller 
fullt behov for bistand. De som har problemer med matinntak har verdien 1 på denne variabelen, de som ikke har problemer med matinntak har verdien 0 . Variabelen hvem gjør matinnkjøp skiller mellom $0=$ familie handler, $1=$ handler selv og $2=$ praktisk bistand/andre handler. De som bor alene har fått verdien 1 på denne variabelen, mens de som bor sammen med noen har verdien 0 . Alder er inndelt i følgende alderskategorier: 1) 63-79 år, 2) 80-84 år og 3) 85-89 år og 4) 90 år og eldre. Alder er ikke inkludert i regresjonsanalysen som er vist i denne artikkelen. Dette fordi det er liten aldersspredning $i$ utvalget og alder viste seg heller ikke å være statistisk signifikant $(p=0,358)$. Egenrapportert helse, plass på dagsenter og bistand fra hjemmesykepleien ble forsøkt inkludert i analysen. Ingen av de nevnte variablene hadde signifikant betydning for pasientenes ernæringsstatus, vi valgte derfor å ekskludere disse variablene fra analysen. "The Variance Inflation Factor» (VIF) benyttes for å identifisere multikollinearitet $i$ en matrise av prediktorer. Den kritiske verdien for VIF blir ofte satt til 10 (30), variabelen bo alene oversteg tallet ti og ble derfor tatt ut av analysen. De andre uavhengige variablene som inngår i den logistiske regresjonsanalysen oversteg ikke den kritiske verdien for VIF. I tillegg har vi også forsøkt å inkludere samspillsledd mellom kjønn og en rekke relevante variabler. Ingen av samspillsleddene var signifikante og er derfor ikke tatt med $i$ analysen.

Fra den logistiske regresjons-

TABELL 1: Deskriptiv statistikk over utvalget, prosentandeler hvis ikke annet er angitt.

( $n=282$ )

\begin{tabular}{ll}
\hline Ernæringsstatus vurdert med MNA skjema, & \\
sumskåre screening del 1 & \\
$25 \%$ persentil & 11 \\
$50 \%$ persentil & 12 \\
$75 \%$ persentil & \\
Ernæringsstatus vurdert med MNA skjema, & \\
samlet vurdering del 1 og del 2 & $47,9(\mathrm{n}=135)$ \\
Normal/ikke i faresonen & $40,4(\mathrm{n}=114)$ \\
Fare for underernæring & $10,3(\mathrm{n}=29)$ \\
Underernært & \\
IPLOS registrering: 3-5 på IPLOS-skalaen & 67,4 \\
3= Middels behov for bistand/assistanse & 28,0 \\
4= Stort behov for bistand/assistanse & 3,6 \\
5= Fullt bistands-/assistansebehov & 71,7 \\
Kvinne & 19,3 \\
Alder & 23,3 \\
63-79 år & 34,0 \\
80-84 år & 23,3 \\
85-89 år & 9,3 \\
90 år og eldre & 70,7 \\
Problemer med matinntak & \\
Bor alene & 56,1 \\
Hvem gjør matinnkjøp & 15,8 \\
Familie & 28,0 \\
Handler selv &
\end{tabular}


i utvalget, henholdsvis 71,7 og 28,3 prosent. 91 prosent av pasientene angir at de ikke hadde fysiske problemer med matinntak. Videre viser tabell 1 at hele 71 prosent bor alene. Til slutt i tabell 1 ser vi at 56 prosent av pasientene får hjelp av familien til å gjøre matinnkjøp, 16 prosent handler selv og 28 prosent får praktisk bistand.

Tabell 2 viser resultatet fra en logistisk regresjonsanalyse av ernæringsstatus hos brukere av hjemmetjenesten i fire utvalgte bydeler i Oslo. Variablene som er brukt i analysen er kjønn, problemer med matinntak og bistand til matinnkjøp. I modell 1 ser vi at menn hadde 49 prosent lavere odds for å være underernært eller det å stå i fare for underernæring enn kvinner, og resultatet er statistisk signifikant. Resultatet av denne analysen peker mot at hjemmeboende kvinner med kognitiv svikt er mer utsatt for underernæring enn hjemmeboende menn med kognitiv svikt.

I modell 2 inkluderer vi variabelen problemer med matinntak. Etter at vi har inkludert
Til slutt i modell 3, inkluderer vi bistand til matinnkjøp. De som foretar matinnkjøp selv har 64 prosent lavere odds for å være underernært eller stå i fare for underernæring sammenliknet med dem som får hjelp til handling fra familien. Det er

\section{Hvem som bidrar ved matinnkjop har sam- menheng med pasientenes ernæringsstatus.}

den nye variabelen i modell 2 er kjønn fremdeles statistisk signifikant. Det å ha problemer med matinntak har naturlig nok signifikant betydning for pasientenes ernæringsstatus. De som ikke har problemer med matinntak har 86 prosent lavere odds for å være underernært eller stå i fare for underernæring, sammenliknet med de som har problemer med matinntak. ingen signifikant forskjell mellom de som får hjelp til handling fra familie eller praktisk bistand. Betydningen av kjønn er fremdeles signifikant etter at vi inkluderte variabelen bistand til matinnkjøp i modellen.

\section{DISKUSJON}

Denne artikkelen har analysert ernæringsstatusen til pasienter og brukere av hjemmetjenesten

TABELL 2: Logistisk regresjonsanalyse av ernæringsstatus (vurdert med MNA skjema) hos brukere av hjemmetjenesten i fire utvalgte bydeler i Oslo.

\begin{tabular}{|c|c|c|c|c|c|c|c|c|c|c|c|c|}
\hline & \multicolumn{4}{|c|}{ Modell 1} & \multicolumn{4}{|c|}{ Modell 2} & \multicolumn{4}{|c|}{ Modell 3} \\
\hline & \multicolumn{4}{|l|}{$(n=276)$} & \multicolumn{4}{|c|}{$(n=271)$} & \multicolumn{4}{|c|}{$(n=268)$} \\
\hline & OR & $95 \% \mathrm{KI}$ & & $p$-verdi & OR & $95 \% \mathrm{KI}$ & & p-verdi & OR & $95 \% \mathrm{KI}$ & & $p$-verdi \\
\hline \multicolumn{13}{|l|}{ Kjønn } \\
\hline Kvinner & 1 & - & - & - & 1 & - & - & - & 1 & - & - & - \\
\hline Menn & 0,506 & 0,297 & 0,863 & 0,012 & 0,441 & 0,250 & 0,778 & 0,005 & 0,515 & 0,286 & 0,925 & 0,026 \\
\hline \multicolumn{13}{|c|}{$\begin{array}{l}\text { Problemer } \\
\text { med mat- } \\
\text { inntak }\end{array}$} \\
\hline $\mathrm{Ja}$ & 1 & - & - & - & 1 & - & - & - & 1 & - & - & - \\
\hline $\mathrm{Nei}$ & & & & & 0,144 & 0,047 & 0,442 & 0,001 & 0,138 & 0,043 & 0,440 & 0,001 \\
\hline \multicolumn{13}{|c|}{$\begin{array}{l}\text { Hvem gjør } \\
\text { matinnkjøp }\end{array}$} \\
\hline Familie & & & & & & & & & 1 & - & - & - \\
\hline $\begin{array}{l}\text { Handler } \\
\text { selv }\end{array}$ & & & & & & & & & 0,365 & 0,171 & 0,779 & 0,009 \\
\hline $\begin{array}{l}\text { Praktisk } \\
\text { bistand/ } \\
\text { andre }\end{array}$ & & & & & & & & & 1,246 & 0,697 & 2,227 & 0,459 \\
\hline
\end{tabular}


med kognitiv svikt eller demenssykdom i fire utvalgte bydeler i Oslo. Resultatene viser at halvparten av denne gruppen er underernært eller står i fare for underernæring. Vårt funn om at en betydelig andel av hjemmeboende pasienter med kognitiv svikt er underernært eller står i fare for underernæring, er i samsvar med tidligere studier som har studert ernæringstilstanden blant eldre hjemmeboende $(11,16,31-33)$. De nevnte studiene viser at pasienter med kognitiv svikt eller demenssykdom har høy risiko for å utvikle underernæring, spesielt hjemmeboende pasienter med demens.

Et annet sentralt funn i vår som bidrar ved matinnkjøp har sammenheng med pasientenes ernæringsstatus. De pasientene som foretar matinnkjøp selv har betydelig lavere sannsynlighet for å være underernært eller stå i fare for underernæring sammenliknet med dem som ikke foretar matinnkjøp selv. Ettersom vi kun har tverrsnittsdata kan vi ikke si noe sikkert om årsaksforholdet mellom det å handle selv og fare for underernæring. Dette funnet kan tolkes på mange måter, men en nærliggende forklaring er at denne gruppen har bedre helse og ernæringsstatus. Av den grunn er de i bedre stand til å handle selv og trenger derfor ikke bistand fra andre. Videre

\section{Det å være kvinne og det å ha problemer med matinntak har en sterk sammenheng med underernæring.}

undersøkelse er at kjønn har signifikant betydning for sannsynligheten for å være underernært eller stå i fare for underernæring. Kvinner har betydelig høyere sannsynlighet for å stå i fare for underernæring eller være underernært sammenliknet med menn, dette er også vist $\mathrm{i}$ andre studier (13-15).

Problemer med matinntak viste seg også å ha stor betydning for sannsynligheten for å være underernært eller stå i fare for underernæring. De pasientene som oppga fysiske problemer med å få i seg mat, var særdeles utsatte for underernæring, noe som ikke er veldig overraskende. Andre studier bekrefter også at problemer med matinntak på grunn av dårlig tannstatus kan føre til dårlig ernæring (18).

Videre fant vi også at hvem kan det også være slik at de som er underernærte eller somatisk syke ikke har krefter til å handle selv. En annen mulig forklaring er at det å kunne planlegge, handle sin egen mat og velge selv hva man skal spise, samtidig som en er i stand til å innta måltidet, faktisk bidrar til bedre matlyst og reduserer risikoen for underernæring.

Hovedfunnene i denne artikkelen er at det er en betydelig andel av hjemmeboende pasienter som er underernærte eller står i fare for å bli underernærte. Et annet sentralt funn i denne artikkelen er at det å være kvinne og det å ha problemer med matinntak har en sterk sammenheng med underernæring. Våre resultater peker mot at helsepersonell må være spesielt oppmerksomme på pasienter som har problemer med matinntak, og da spesielt kvinner. Denne pasientgruppen har behov for ekstra oppfølging med hensyn til ernæring, for å forebygge store vekttap og underernæring.

\section{Metodekritiske betraktninger}

En styrke ved studien er svarprosenten på 63,4. En utfordring under datainnsamlingen var at pasientene hadde hukommelsessvikt med behov for bistand. Dette innebar redusert innsikt i og forståelse av egen ernæringsstatus, når det gjaldt å besvare spørsmål på inntak av mat og drikke. Svar knyttet til synet på egen ernæringsstatus og inntak av ulike sorter mat blir derfor usikre og kan ikke inkluderes i våre analyser. En styrke er at mange pleiere hadde sine faste pasienter og innsikt $\mathrm{i}$ deres behov for bistand og evne til både å gjenkjenne mat og å spise den. Ettersom pleierne kjente pasientene godt kunne de bistå pasientene med å besvare spørsmålene om mat og drikke. For dem som ikke var i stand til å svare selv hadde pleierne rimelig god oversikt over pasientenes matinntak og kunne derfor besvare spørsmålene på vegne av pasienten.

\section{KONKLUSJON}

I denne artikkelen har vi belyst underernæring og fare for underernæring blant hjemmeboende pasienter med kognitiv svikt eller demenssykdom. Våre funn viser at underernæring er svært utbredt i denne pasientgruppen. Omkring halvparten av pasientene $i$ vårt utvalg var underernærte eller sto i fare for underernæring. Det å være kvinne og ha problemer med matinntak viste seg å ha en klar sammenheng med underernæring. Videre viser våre resul- 
tater at pasienter som foretar matinnkjøp selv har betydelig lavere sannsynlighet for å være underernærte enn de som ikke foretar matinnkjøp selv. Det vil derfor være heldig at pasienter med behov for bistand tilbys mulighet for å handle sammen med hjemmehjelpen slik at de selv kan velge mat de gjenkjenner og vil spise. Det er viktig at helsepersonell har rutiner for å innhente data relatert til ernæringsstatus hos denne sårbare pasientgruppen. Likeså er det avgjørende at pleiere og pårørende er kjent med de nevnte risikofaktorene, og at tiltak blir iverksatt på et tidlig tidspunkt for å forebygge og forhindre alvorlig underernæring og sykdom som følge av dette.

\section{REFERANSER}

1. Amella EJ. Feeding and hydration issues for older adults with dementia. The Nursing Clinics of North America. 2004; 39: 607-23.

2. Rekve HK. Tilrettelegging av måltider for personer med atferdsforstyrrelser og psykiske symptomer ved demens. Tidsskrift for sykepleie i geriatri og demens. 2009;1:18-20.

3. Husom, N. Nytt redskap for diagnostisering av demens. Tidsskrift for Den norske legeforening. 2002;8:122:861-2. 4.Smedshaug B G. Ernæring til eldre - med bakgrunn i nasjonale retningslinjer for forebygging og behandling av underernæring. Tidsskrift for sykepleie i geriatriog demens. 2009;1:6-10.

5. Sørbye L W, Scholl M, Finne-Svori H. Unintended weight loss in the elderly living at home: the aged in home care project (ADHOC). The Journal of Nutrition, Health \& Aging. 2008;12:10-16

6. Sørbye L W. Hjemmetjnester til eldre i Bærum og Ullern. Sammenliknende data fra AdHOC studiet. Oslo: Diakonhjemmets høyskole. 2003.

7. Lov om kommunale helse - og omsorgstjenester $\mathrm{m}$. $\mathrm{m}$ lhelse og omsorgstjenesteloven] 2012 http:// www.lovdata.no/cgi-wift/wiftldrens?/app/gratis/www/docroot/all/ hl-20110624-001.html

8. Helsedirektoratet. Nasjonale faglige retningslinjer for forebygging og behandling av underernæring. 2009, IS-1580.

9. Fagerström C, Palmquist R, Carls- son J, Hellstrõm Y. Malnutrition and cognitive impairment among people 60 years and above living in regular housing and in special housing in Sweeden: A population-based cohort study. International Journal of Nursing Studies. 2011; 48 (7): 863-71.

10. Meijers JM, Schols JM, van der Bokhorst-de van der Schueren MA, Dassen T, Jassen MA, Halfens RJ. Malnutrition in The Netherlands: results of the annual Dutch national measurement of care problems. The British Journal of Nutrition: 2009; 101: 417-23. 11. Kvamme J-M, Grønli O, Florholmen, Jacobsen B. Risk of malnutrition is associated with mental health symptoms in community living elderly men and women: The Tromsø Study. BMC Psychiatry. 2011; 11: 112-20.

12. Norman K, Picard C, Lochs H. Prognostic impact of disease-related malnutrition. Clin Nutr 2008; 27: 5-15. 13. Suominen M, Muurinen S, Pitkala H. Malnitrition and associated factors among aged residents in all nursing homes in Helsinki. European Journal of Clinical Nutrition. 2005; 59: 578-83. 14. Sund-Levander M, Grodzinsky $E$, Wahren, L K. Gender differences in predictors of survival in elderly nursing-home residents: a 3 -year follow up. Scand J Caring Sci. 2007; 21:18-24. 15. Khater MS, Abouelezz F. Nutritional status in older adults with mild cognitive impairment living in elderly homes in Cairo, Egypt. The Journal of Nutrition, Health \& Aging. 201;15:104-8. 16. Biolettea C, Bergamaschini L, Arienti R, Spreakfico S, Vergani C. Caregiver burden as a short-term predictor of weight loss in older outpatients suffering from mild to moderate Alzheimer's disease: A three months follow-up study. Aging \& Mental Health. 2010; 14: 481-8.

17. Kim JM, Stewart R, Prince M, Kim S W, Yang S J, Shin S, Yoon J S. Dental health, nutritional status and recentonset dementia in a Korean community population. International Journal of Geriatric Psychiatry. 2007; 22: 850-5. 18. Kuosma K, Hjerrild J, Pedersen $P \mathrm{U}$, Hundrup $\mathrm{YH}$. Assessment of the nutritional status among residents in Danish nursing home - health effects of a formulated food and meal policy. J Clin Nurs. 2007;17:2288-93.

19. Keller HH, Smith D, Kasdorf C, Martin L S, Cook C, Genoe R. Nutrition Education and Resources for Dementia Care in Community. American Journal of Alzheimer's Disease and Other Dementia. 2008;23:13-23.

20. Berry EM, Marcus E L. Disorders of eating in elderly. Journal of Adult Development. 2000;7:87-99.

21. Watson R. Measuring freding dif- ficulties in patients with dementia; perspectives and problems. J Adv Nurs. 1993;18:25-31.

22. Aselage B M B. Measuring difficulties: eating, freding and meal behaviors in older adults with dementia. J Clin Nurs. 2010;19 621-31.

23. Chang C C, Roberts B L. Cultural Perspectives in Feeding Difficulity in Taiwanese Elderly With Dementia. Journal of Nursing Scholarship. 2008;40:235-40

24. Mamhidir A G, Karlsson I, Norberg $A$. Weight increase in patients with dementia, and alteration in meal routines and meal environment after integrity promoting care. J Clin Nurs. 2007;16: 987-96.

25. Pasman H R, The B A, Philipsen B D, van der Wal G, Ribbe M W. Feeding nursing home patients with severe dementia: a qualitative study. J Adv Nurs. 2003;42:304-11

26. Inoue K, Kato M. Usefulness of the Mini Nutritional Assessment (MNA) to evaluate the nutritional status of Japanese frail elderly under home care. Geriatr Gerontol Int. 2007;7:238-44

27. Guigoz Y, Laugue S, Vellas B J. Identifying the elderly risk for malnutrition. The Mini Nutritional Assessment. Clin Geriatr Med. 2002;18:737-57

28. Ranhoff $A H$, Gjøen A, Mowe $M$. Screening for malnutrition in elderly acute medical patients: the usefulness of MNA-SF. The Journal of Nutrition, Health \& Aging: 2005;9:221-5.

29. Mowe M, Diep L, Bøhmer T. Greater seven-year survival in very aged patients with body mass index between 24 and $26 \mathrm{~kg} / \mathrm{m}^{2}$. Journal of the American geriatrics Society. 2008;56:359-60.

30. Montgomery DC, Peck EA, Vining GG. Introduction to Linear Regression Analysis, 3rd Ed. 2001, John Wiley and Sons.

31. Umegaki H, Suzuki Y, Yanagawa M, Nonogaki Z, Nakashima H, Kuzuga M, Endo H. Cognitive impairments and functions declines in older adults at high risk for care needs. Geriatrics Gerontology International. 2012;13:7782.

32. Lee KS, Cheong HK, Kim EA, Kim $\mathrm{KR}$, Oh $\mathrm{BH}$, Hong $\mathrm{CH}$. Nutritional risk and cognitive impairment in the elderly. Archives of Gerontology and Geriatrics. 2007;48:95-9

33. Chang CC, Chan LC. Effects of a freding skills training programme on nursing assistents and dementia patients. $\mathrm{J}$ Clin Nurs. 2005;14:1185-92.

Les kommentaren på side 308 》 